\title{
Antiproliferative therapy with sirolimus and propranolol for congenital vascular anomalies in newborns (Case reports)
}

\author{
CĂTĂLIN CÎRSTOVEANU ${ }^{1,2}$, ANA MIHAELA BIZUBAC ${ }^{1,2}$, CRISTINA MUSTEA $^{1}$, \\ ŞTEFAN MANOLACHE ${ }^{1}$, ALEXANDRA ISTRATE-BÂRZAN ${ }^{1}$, DOINIȚA SFRIJAN ${ }^{2,3}$, \\ VERONICA MARCU $^{4}$, DAN-ALEXANDRU IOZSA ${ }^{5,6}$ and RADU-IULIAN SPĂTARU ${ }^{5,6}$
}

\author{
${ }^{1}$ Neonatal Intensive Care Unit, 'Marie S. Curie' Emergency Clinical Hospital for Children, 077120 Bucharest; \\ ${ }^{2}$ Department of Pediatrics, 'Carol Davila' University of Medicine and Pharmacy, 050474 Bucharest; \\ ${ }^{3}$ Oncology Department, ${ }^{4}$ Radiology Department and ${ }^{5}$ Pediatric Surgery Department, \\ 'Marie S. Curie' Emergency Clinical Hospital for Children, 077120 Bucharest; \\ ${ }^{6}$ Department of Pediatric Surgery and Orthopedics, 'Carol Davila' University \\ of Medicine and Pharmacy, 050474 Bucharest, Romania
}

Received May 31, 2021; Accepted June 30, 2021

DOI: $10.3892 /$ etm.2021.10531

\begin{abstract}
We present a series of four newborns diagnosed with complicated congenital vascular anomalies, with different localization: Congenital lymphatic malformation (CLM) on the left hemithorax extending on the left upper limb; congenital hepatic hemangioma $(\mathrm{CHH})$ with important complications in the first 7 weeks of life; Kaposiform hemangioendothelioma (KHE) of the left lower limb complicated with Kasabach Merritt phenomenon (KMM) and most probable diffuse capillary malformation with overgrowth (DCMO). All patients were treated with combined antiproliferative therapy with sirolimus and propranolol. The initial dose of sirolimus was $0.45-0.5 \mathrm{mg} / \mathrm{m}^{2}$ with doses adjusted according to plasmatic levels. Therapeutic intervals of sirolimus were considered at plasmatic levels of 7-12 ng/ml. Our aim was to use the lowest therapeutic dose in order to avoid possible side effects. Propranolol was initiated in doses of $0.5-1.0 \mathrm{mg} / \mathrm{kg} /$ day and was increased up to $3.0 \mathrm{mg} / \mathrm{kg} / \mathrm{day}$ depending on tolerability. Following two months, every patient
\end{abstract}

Correspondence to: Dr Ana Mihaela Bizubac, Neonatal Intensive Care Unit, 'Marie S. Curie' Emergency Clinical Hospital for Children, 20 Constantin Brâncoveanu Boulevard, 077120 Bucharest, Romania E-mail: anamihaeladogaru@yahoo.com

Abbreviations: CLM, congenital lymphatic malformation; $\mathrm{CHH}$, congenital hepatic hemangioma; KHE, Kaposiform hemangioendothelioma; KMP, Kasabach-Merritt phenomenon; DCMO, diffuse capillary malformation with overgrowth; CVM, congenital vascular malformation; KTS, Klippel Trenaunay Syndrome; $\mathrm{PI} 3 \mathrm{~K}$, phosphatidylinositol 3-kinase; AKT, protein kinase B (also PKB); mTOR, mammalian target of rapamycin receptor; HDL, high-density lipoprotein; VEGF, vascular endothelial growth factor

Key words: congenital vascular anomalies, vascular malformations, antiproliferative therapy, propranolol, sirolimus showed a marked reduction in the size of the mass, improvement in overall appearance or even calcification in the liver vascular tumor. No patient showed life threatening side effects to the treatment. Hypertriglyceridemia was the only side effect noted in all patients. This is in accordance with several international studies, which try to demonstrate the importance of sirolimus in neonatal vascular malformations in monotherapy or combined with different drugs.

\section{Introduction}

Vascular anomalies describe two pathological entities: Congenital vascular malformations (CVMs) and vascular tumors (1). Depending on the presence of arterial flow, these can be described as fast-flow [vascular malformations-arteriovenous malformation, arteriovenous fistula, and complex malformations such as Parkes-Weber syndrome and vascular tumors (hemangiomas or neoplasms such as Kaposiform hemangioendothelioma (KHE), hemangiopericytoma, angiosarcoma)] and low-flow, benign lesions [venous malformations, lymphatic malformations, capillary malformations such as diffuse capillary malformation with overgrowth (DCMO, combined/complex malformations, such as Klippel-Trenaunay syndrome (KTS), Proteus syndrome, CLOVES syndrome, Sturge-Weber syndrome] (2-4).

CVMs result from a failure in angiogenesis during the development of the vascular system; they are present at birth and usually grow with the infant (3). If arterial flow is observed through imaging studies, differential diagnosis includes arterio-venous malformations, arteriovenous fistula or a complex vascular malformation (2).

Capillary malformations are clinically diagnosed and present as port-wine stains and telangiectasia. Most of the times they are isolated anomalies but can be part of a complex vascular malformation (1,3-5).

Venous malformations and complex malformations with a venous component have a variable presentation depending 
on their depth and associated complications. Complications associated with venous malformations are venous stasis, thrombosis and localized intravascular coagulopathy (6). Despite being congenital, venous malformations usually manifest later in childhood because they grow with the patient. Upon physical examination, they appear as compressible bluish colored, sponge-like masses $(3,6)$.

Lymphatic malformations appear following aberrant morphogenesis of primordial lymphatic structures and can be classified as microcystic or macrocystic (7-9). Lymphatic malformations or complex vascular malformations with a lymphatic component can lead to disfigurement caused by tissue hypertrophy and skeletal overgrowth; depending on the organs involved, they can lead to chylous effusions with organ compromise. Large lesions can be complicated by fluid loss, hypoproteinemia, bleeding, and infection (10).

Vascular tumors develop from the endothelium; they are fully formed at birth and are divided into congenital hemangiomas that can either be rapidly involuting or non-involuting and more complex tumors such as KHE or tufted angioma (2). Complex vascular neoplasms are infiltrative lesions and can cause Kasabach-Merritt phenomenon (KMP). KMP is a consumptive coagulopathy syndrome consisting of platelet trapping with profound thrombocytopenia, enlargement of the lesion and significant hypofibrinogenemia (10-12).

Currently, there is no established standard of care for the treatment of vascular anomalies. Therapy is guided based on symptoms and association of complications. Management is comprised of surgical excision, sclerotherapy or embolization $(2,3,13)$. Medical management includes steroids, vincristine and interferon with potential significant side effects in infants, especially neurotoxicity $(10,14)$. Propranolol represents the first line of treatment for patients with vascular tumors such as hepatic hemangiomas (14-16).

Ideally, therapies for vascular anomalies would target specific cellular pathways involved in abnormal cellular proliferation and growth.

In the last few years, multiple cases have been reported for the safety of sirolimus as a therapeutic option for various congenital vascular anomalies $(9,10,12,17-23)$. The phosphatidylinositol 3-kinase (PI3K)/protein kinase B (AKT) signaling pathway is pivotal for cellular functions such as growth and survival and has been demonstrated to be involved in normal vascular development and angiogenesis $(24,25)$. Extracellular signals activating the PI3K/AKT pathway transfer signals to mammalian target of rapamycin receptor (mTOR) which, in return, increases expression of vascular endothelial growth factors (VEGF)-A and VEGF-C. VEGF-A and VEGF-C are regulators of both angiogenesis and lymphangiogenesis, promoting protein synthesis, cellular growth and proliferation $(9,10,24,25)$. Over time, inhibitors that target this signaling pathway have been shown to reduce VEGF secretion and angiogenesis, thus making them a suitable option for the treatment of CMVs $(24,25)$. Sirolimus is a direct antagonist of mTOR that acts by blocking the downstream synthesis of the PI3K/AKT/mTOR pathway resulting in antitumoral and antiangiogenic effects by impairing VEGF production $(10,26)$. mTOR receptors have been shown to be overexpressed in vascular tumors, which makes sirolimus suitable as a treatment option for vascular malformations (24). Similar to sirolimus, propranolol, a nonselective $\beta$-adrenergic receptor antagonist that causes vasoconstriction and used as first line of treatment for congenital hemangiomas, inhibits angiogenesis and promotes apoptosis (14) by acting on the PI3K/AKT signaling pathway (27). Studies have shown that protein levels and mRNA of both PI3K and AKT were decreased after propranolol treatment, thus suggesting that a reduction in hemangiomas is related to the inhibition of PI3K and AKT (27-29).

\section{Case reports}

We analyzed 4 patients admitted to the Neonatal Intensive Care Unit of 'Marie Curie' Emergency Clinical Hospital for Children, Bucharest, Romania between August 2019 and September 2020. All patients were diagnosed with CVMs and treated with combined antiproliferative therapy with propranolol and sirolimus. We analyzed the medical records and summarized the date available into a case series. Our aim was to monitor the patient clinical and radiological responses and possible adverse reactions to the therapy and demonstrate the treatment safety in comparison with other cases reported in the literature. All patients were started on oral propranolol at $1 \mathrm{mg} / \mathrm{kg} /$ day with doses adjusted up to $3 \mathrm{mg} / \mathrm{kg} /$ day according to the tolerance and sirolimus at an initial dose of $0.4 \mathrm{mg} / \mathrm{m}^{2}$ with doses tired according to plasmatic levels. Blood tests were drawn every other week and then monthly to check for possible side effects.

All of our patients were females, admitted to our unit between 1 and 21 days of life. One patient was diagnosed prenatally through fetal-magnetic resonance imaging while 3 newborns were diagnosed in our unit. All patients had distinct congenital vascular anomalies: 1 patient was diagnosed with congenital lymphangioma of the left hemithorax and left upper arm; 1 patient with $\mathrm{CHH}$ complicated with liver failure; 1 patient with DCMO; and 1 patient with KHE of the left lower limb. Surgical intervention was intended for 2 patients and later postponed because of the high risk of negative outcomes. Treatment was initiated between 4 days of age and 7 weeks. Response to treatment was noted beginning with the first days of therapy in all patients through changes in the overall aspect and size of the mass, changes in the overlaying skin, and improved mobility. Plasmatic levels of sirolimus were monitored at 7 days of treatment and every other week for the duration of stay in our unit. After a stable level was achieved, plasmatic levels were monitored monthly. Plasmatic levels of sirolimus were difficult to maintain in the recommended ranges. All patients had initially a higher plasmatic level that later decreased. Hypertriglyceridemia was the only side effect observed in all four patients. Duration of treatment varied between 27 weeks and 20 months. Three patients still undergo the treatment while for one patient the treatment was stopped after 48 weeks after complete calcification of the liver mass.

Case 1. A female baby was diagnosed prenatally through fetal MRI with lymphatic malformation on the left hemythorax and left upper arm. The newborn was transferred to our unit at $21 \mathrm{~h}$ of life, hemodynamically stable, breathing unaided. On inspection, she presented with a giant lesion on the left hemithorax $(\sim 30 / 25 \mathrm{~cm})$ extending to the left upper limb; overlaying skin was purplish and there was a central area of telangiectasis (Fig. 1A). There were no differences in color or temperature 

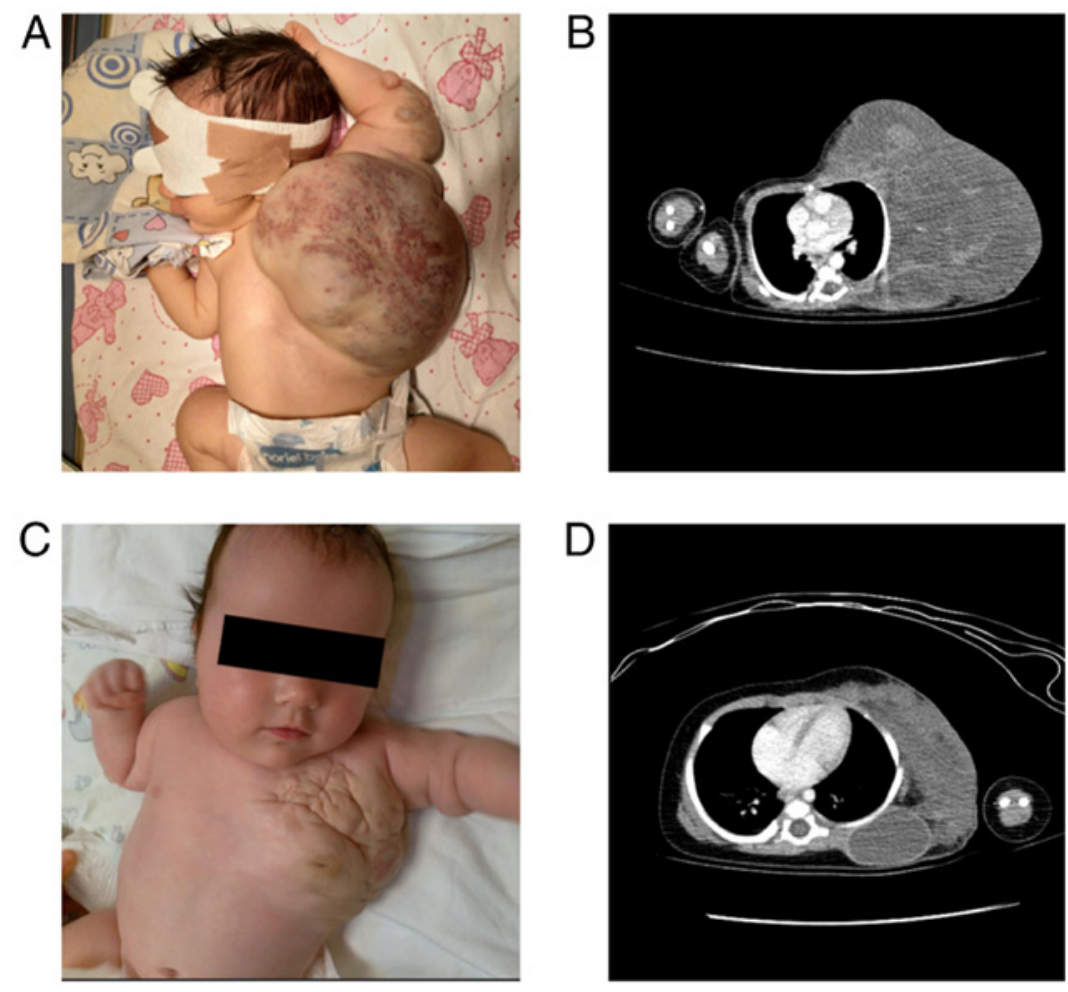

Figure 1. Case 1. Angio-CT on admittance (A and B) vs. at 9 weeks of treatment (C and D) showed significant reduction in the size mostly through reduction of the cystic component. CT, computed tomography.

between the two upper limbs; grasping reflex and spontaneous movements were present.

Chest angio-computed tomography (CT) at 4 days of life (Fig. 1B) showed a massive [12/8.5 cm (axial), $13.8 \mathrm{~cm}$ (longitudinal)] soft tissue, cystic lesion with fine septal and intralesional hemorrhage. The lesion infiltrated the interscapulo-costal space without damaging the scapulo-humeral articulation. The CT scan revealed only one fine vascular branch inside the mass.

Surgical removal of the lesion was attempted and later postponed following significant hemorrhage after a fine needle aspiration was performed in the operating room. Monotherapy with propranolol was started on admittance but after 4 weeks of treatment there were no visible effects. On the 20th day of life, we began combination therapy with sirolimus $\left(0.4 \mathrm{mg} / \mathrm{m}^{2}\right.$ per dose, twice daily) and propranolol. After the first week of combined therapy, the overall size of the mass shrunk, the overlying skin changed to a natural color and the arm movement improved.

Plasmatic levels of sirolimus were monitored and varied between 2.7-29 $\mu \mathrm{g} / \mathrm{l}$ with doses adjusted between 0.32 and $0.66 \mathrm{mg} / \mathrm{m}^{2}$.

The only side effects noted were a slight tendency to prolonged dyslipidemia with hypertriglyceridemia and decreased levels of high-density lipoprotein (HDL). Massive reduction of the lesion size was noted at 3 months of age (Fig. 1C). Control angio-CT performed at that time (11 weeks of combined therapy) showed a reduction in mass size predominantly through reduction of the cystic component (maximum axial size, 10/5.7 cm) (Fig. 1D). The patient was discharged at home at $3 \frac{1}{2}$ months of age, continuing the combined antiproliferative therapy. Currently, she is still undergoing treatment going on 20 months of combined therapy and is on clinical, pharmacological and radiological follow-up.
Case 2. A female baby at clinical examination presented with abdominal distention and a palpable mass in the right hypochondrium. She was diagnosed at the local maternity department with $\mathrm{CHH}$. The diagnosis was based on the angio-CT that showed characteristic findings suggestive of $\mathrm{CHH}$ : A well-defined solitary lesion of $\sim 66.5 / 61.5 / 66 \mathrm{~mm}$ in the central hilar portion of the liver with centripetal enhancement and central sparing (Fig. 2A). Her evolution was complicated by moderate anemia, thrombocytopenia, progressive hepatic cytolysis, cholestatic and inflammatory syndromes. She was transferred to our clinic at 21 days of life.

Upon admittance, the patient was breathing smoothly, had a stable heart rate and was hemodynamically stable; she was moderately jaundiced, had a distended abdomen and a palpable mass of about $7 / 6 \mathrm{~cm}$ was found on clinical examination.

Abdominal ultrasound (US) on admittance showed a central hilar lesion occupying the Vth and VIth liver segments and partially the IVth, VIIth and VIIIth segments; the tumor had well-defined margins, was heterogenous and had a central inhomogeneous necrotic zone surrounded by a peripheral, well vascularized area (Fig. 2C). Echocardiographic findings were normal.

Upon arrival, she was started on oral propranolol with an initial dose of $1 \mathrm{mg} / \mathrm{kg} /$ day which was increased slowly until a maintenance dose of $3 \mathrm{mg} / \mathrm{kg} /$ day was reached. Ursodeoxycholic acid was initiated for the cholestatic syndrome at a dose of $10 \mathrm{mg} / \mathrm{kg} / \mathrm{day}$. In evolution, the patient exhibited an associated feeding intolerance with frequent postprandial regurgitation and vomiting because of the mass effect of the lesion.

Abdominal US studies showed no visible changes after 4 weeks of treatment. Liver function tests remained elevated over the normal reference ranges and she presented with persistent hypoalbuminemia, for which albumin infusion was 

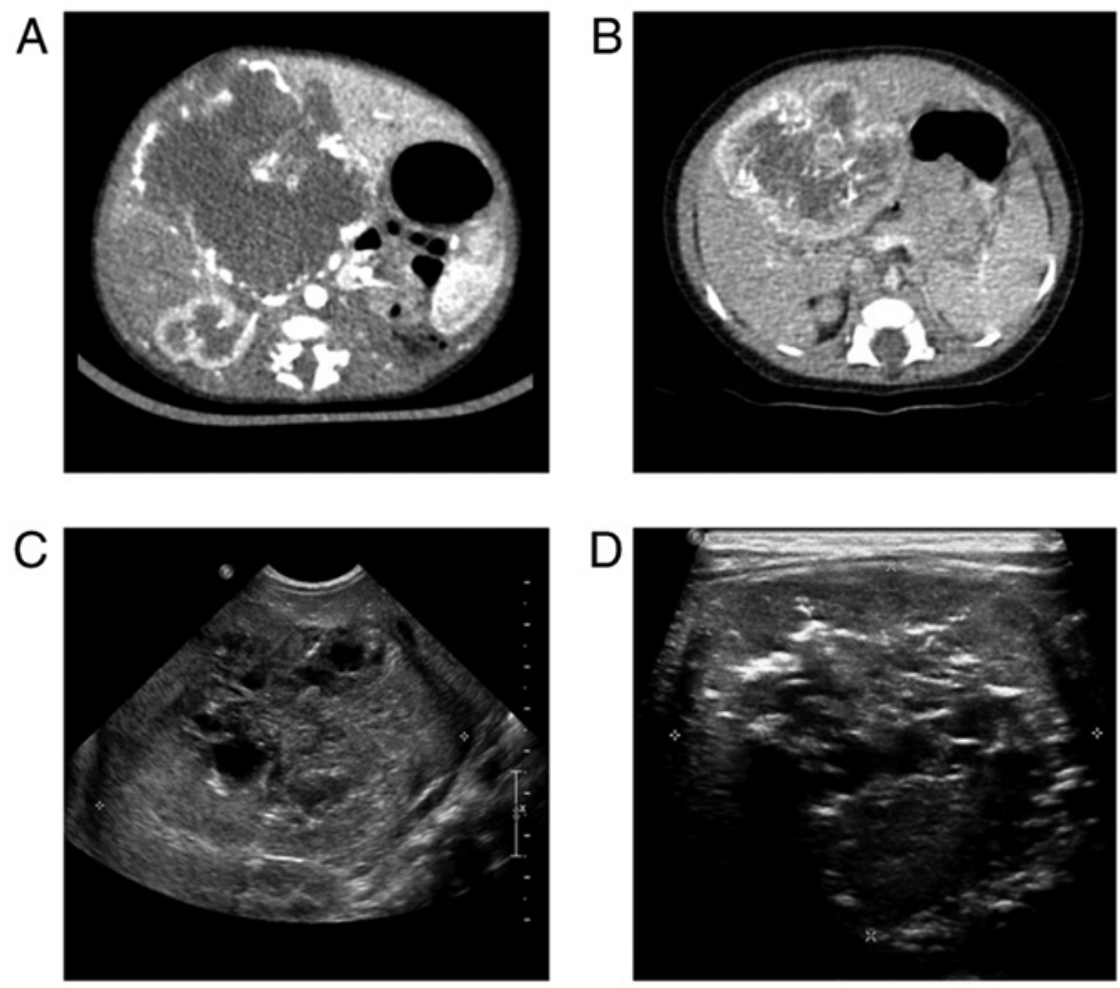

Figure 2. Case 2. (A and B) Abdominal angio-CT scan showing a solitary hepatic mass with centripetal enhancement and central sparing vs. after 5 weeks of combined antiproliferative therapy which showed a reduction in size with increased intralesional calcifications. (C and D) Abdominal ultrasound (US) on admittance showing a giant liver lesion with a central necrotic zone surrounded by a peripheral well vascularized area vs. US at 2 weeks of combined therapy which showed increased central necrotic area and intralesional calcifications. CT, computed tomography.

needed. Cholestasis persisted over the course of the treatment with propranolol.

Giving the large size and central localization of the lesion, after a multi-disciplinary hearing composed of the neonatology, pediatric surgery and radiology teams, a decision was made to postpone the surgical treatment, given the high risk for a negative outcome.

At the age of 1 month and 3 weeks, the patient was started on combined antiproliferative therapy with oral sirolimus $\left(0,4 \mathrm{mg} / \mathrm{m}^{2}\right.$ per dose, twice daily) and propranolol ( $\left.3 \mathrm{mg} / \mathrm{kg} / \mathrm{day}\right)$. The dose of sirolimus ranged between 0.35 and $0.8 \mathrm{mg} / \mathrm{m}^{2}$, adjusted according to plasmatic levels (4.4-16.73 $\mu \mathrm{g} / \mathrm{l})$.

Abdominal US after 1 week of combined antiproliferative treatment showed diminished intratumoral vascularization and new necrotic areas inside the tumoral tissue. After 2 weeks of treatment, a reduction in size was noticeable $(63 / 56 / 57 \mathrm{~mm}$ compared to $\sim 66.5 / 61.5 / 66 \mathrm{~mm}$ ) (Fig. 2D). Side effects noted were persistent dyslipidemia with hypertriglyceridemia and low HDL-cholesterol levels. Control angio-CT scan after 4 weeks of treatment showed moderate reduction of mass size $(63 / 54 / 51 \mathrm{~mm})$ and multiple intratumoral calcifications (Fig. 2B). The patient was discharged at home at 3 months and 1 week of age on oral propranolol $(3.5 \mathrm{mg} / \mathrm{kg} /$ day $)$ and sirolimus $\left(\sim 0.55 \mathrm{mg} / \mathrm{m}^{2}\right)$. At present the patient is well at home.

After 30 weeks of treatment, abdominal US showed that the mass shrunk to half of its original size (current size 32/29 mm vs. $\sim 66.5 / 61.5 / 66 \mathrm{~mm}$ at birth) and is fully calcified.

Combined antiproliferative therapy was stopped after 48 weeks of treatment. Currently she is under clinical and radiological follow-up.
Case 3. A female newborn presented with a giant mass encompassing the left thigh, knee and calf. In evolution, the mass extended upwards to the inguinal region and downwards to the distal $1 / 3$ of the calf and foot; the limb became infiltrated with purplish overlaying skin and tender to touch. She was transferred to our unit at 4 days of age, breathing unaided and hemodynamically stable. Upon inspection, the left lower limb was swollen. A giant mass was noted with ill-defined margins, purplish in color with overlaying petechia and telangiectasis. The limb was tender to touch and warmer than the right lower limb; the left thigh girth upon arrival was $\sim 25 \mathrm{~cm}$ compared to $11 \mathrm{~cm}$ around the right thigh, and active movement of the left limb was limited (Fig. 3A). Peripheral pulses were present.

Laboratory tests showed profound thrombocytopenia (PLT $5,000 / \mathrm{mm}^{3}$ ) and coagulation disturbances requiring administration of FFP and platelet transfusions. Upon arrival, she was started on combined antiproliferative therapy with propranolol $\left(1 \mathrm{mg} / \mathrm{kg} /\right.$ day) and sirolimus (starting dose $\left.0.4 \mathrm{mg} / \mathrm{m}^{2}\right)$ in association with methylprednisolone $(2 \mathrm{mg} / \mathrm{kg} /$ day $)$.

Angio-CT scan performed on admission showed a massive hypervascular, relatively well-defined lesion encompassing the left thigh and knee that receives arterial flow from the inferior segment of the left femoral artery and left popliteal artery with early enhancement of the femoral vein; soft tissue edema of the left labia and thigh was present (Fig. 3B).

Response to treatment was noted starting the first days of therapy. Upon inspection, the foot and calf were slowly normalized in regards to color, swelling of the limb was diminished as well as the petechiae and telangiectasis, margins of the lesion became well defined, encompassing $2 / 3$ distal thigh and $1 / 3$ 

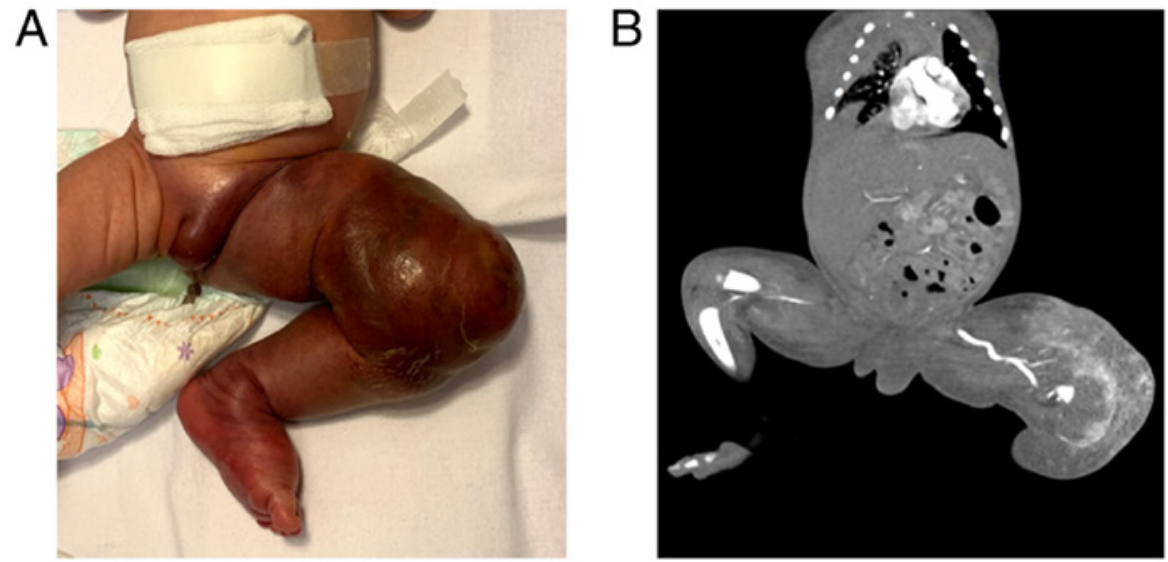

Figure 3. Case 3. (A) Presentation on admittance. (B) Angio-CT at 4 days of life showing a giant hypervascular lesion in the left lower limb with early enhancement of the femoral vein. CT, computed tomography.
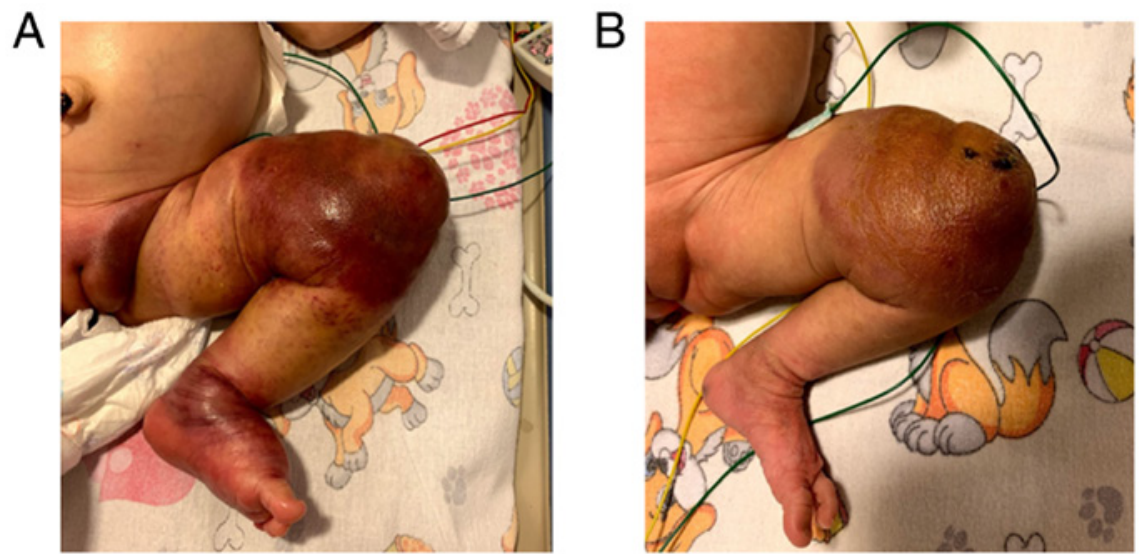

Figure 4. Case 3. Clinical presentation after (A) 4 days and (B) 2 weeks of combined antiproliferative therapy.

proximal calf (Fig. 4A and B). Platelet count increased gradually in the first 3 weeks of treatment and normalized after 4 weeks of combined therapy when the PLT count was elevated $>200,000 / \mu 1$. Corticosteroid therapy was tapered over the course of 4 weeks and stopped when the platelets reached a normal value.

After 11 weeks of combined antiproliferative therapy, during which the patient showed good response to therapy, her status was complicated with swelling of the whole left lower limb including the left major labia. The diameter of the thigh increased from 24 to $31 \mathrm{~cm}$ in a week. Mobility of the limb was good, overlaying skin color was normal and there was local warmth compared to the contralateral limb. Laboratory tests were normal. Doppler-US of the leg showed no arterial or venous obstruction; control angio-CT showed diffused edema of the leg without changes in tumor size.

Propranolol and sirolimus doses were doubled and methylprednisolon for 4 weeks was reintroduced with no visible effect.

At 13 weeks of combined therapy, the patient was started on vincristine at $0.05 \mathrm{mg} / \mathrm{m}^{2} /$ week. After 8 rounds of vincristine therapy associated with sirolimus and propranolol, we observed only mild changes in the tumor aspect. Initially, there was a reduction in thigh girth with resolution of labial edema but after 5 rounds of vincristine the thigh girth increased to $32 \mathrm{~cm}$. Because of severe hypertriglyceridemia, we were forced to reduce the dose of sirolimus to $1 \mathrm{mg} / \mathrm{m}^{2}$. Vincristine therapy was discontinued after 8 courses.

Throughout the course of the treatment, sirolimus doses ranged between 0.5 and $2.0 \mathrm{mg} / \mathrm{m}^{2}$ with plasmatic levels of 5.2-14 $\mu \mathrm{g} / \mathrm{l}$.

The patient is a social case and was transferred to a chronic care facility still undergoing combined therapy, being on week 30 of treatment.

Case 4. A female newborn presented in the delivery room with cyanosis predominantly on the inferior limbs, hypertrophy on the left side of the body with port-wine stains on the inferior limbs and trunk. She was transferred to our NICU at 7 days of life with suspicions of DCMO vs. KTS. Upon admission, she was breathing unaided and was hemodynamically stable. Port-wine stains were observed on inspection, predominantly on the left lower limb with extension on the truncal skin, while the left side of the body was hypertrophied apparently through soft tissue overgrowth (Fig. 5A). There was a $2 \mathrm{~cm}$ difference in girth between the left and right inferior limbs.

Laboratory tests found elevated D-Dimers with normal fibrinogen and coagulation studies. She was started on sirolimus $\left(0.5 \mathrm{mg} / \mathrm{m}^{2}\right)$ upon admission and was administered combined antiproliferative therapy starting on day of life 10 . The initial dose of propranolol was $0.5 \mathrm{mg} / \mathrm{kg} / \mathrm{day}$ and it was 

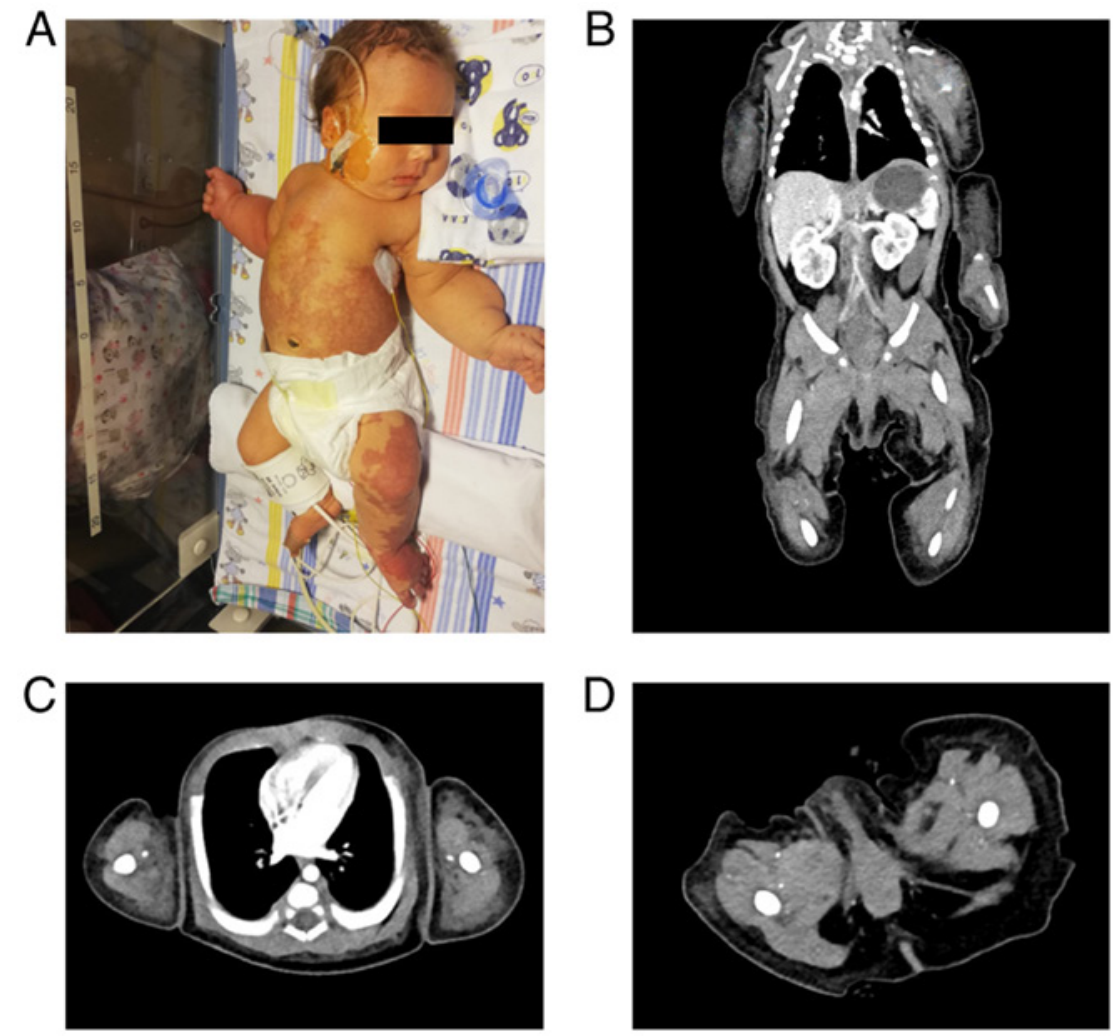

Figure 5. Case 4. (A) Clinical presentation on admittance. (B) Angio-CT scan coronal section showing soft tissue asymmetry on the upper limbs, lower limbs and trunk with ill-delimitated dense areas of fluid/ parafluid consistency. (C and D) Axial sections showing soft tissue asymmetry in both upper and lower limbs. CT, computed tomography.

slowly increased up to $3 \mathrm{mg} / \mathrm{kg} / \mathrm{day}$. Whole exome sequencing was performed and came back negative for KTS.

Angio-CT scan performed at 3 weeks of life showed soft tissue asymmetry on the limbs, thorax and abdominal wall and diffusely delimitated dense areas of fluid/parafluid consistency in the soft tissue, without any signs of associated vascular anomalies (arterial or venous) (Fig. 5B-D). CT scans incidentally found incomplete transposition of the inferior vena cava to the left of the aorta in the infrarenal segment (suprarenal segment of the IVC at the right of the aorta).

After 7 days of treatment, port-wine stains started to become paler and the diameter of both left limbs decreased mildly. The sirolimus dose was tapered according to the plasmatic levels. The initial dose of $0.4 \mathrm{mg} / \mathrm{m}^{2}$ was decreased to 0.3 and then $0.2 \mathrm{mg} / \mathrm{m}^{2}$ based on plasmatic levels that ranged from 16.8 to $26 \mu \mathrm{g} / \mathrm{l}$. The only side effect noted was inconsistent hypertriglyceridemia.

The patient was discharged at home at 7 weeks of life. Currently, she is on week 27 of combined therapy and is on clinical and pharmacological follow-up.

\section{Discussion}

Congenital vascular anomalies are a heterogenous group of pathologies comprised of vascular tumors and CVMs. Reported incidence of CVMs is $0.3-1.5 \%$ while vascular tumors such as hemangiomas appear in $2-3 \%$ of newborns (1).

We reported a case series of four patients admitted to our NICU Unit between August 2019 and September 2020, diagnosed with distinct vascular anomalies [CLM, CHH, KHE and
DCMO] complicated with intralesional bleeding, liver failure or consumptive coagulopathy.

Currently there is no consensus regarding the standard therapy for CVMs, as literature dealing with vascular anomalies consists mainly of case reports. Treatment options are individualized based on the type of malformation, localization, associated symptoms and complications.

Sirolimus formerly known as rapamycin is a mTOR inhibitor with antiproliferative, immunosuppressive and antitumoral effects acting on the mTOR/PI3K/AKT pathway (9). The $\mathrm{mTOR} / \mathrm{PI} 3 \mathrm{~K} / \mathrm{AKT}$ pathway is a cell signaling pathway implicated in both angiogenesis and lymphangiogenesis resulting in cellular growth and vascular proliferation $(19,24,25,30,31)$. Sirolimus inhibits aberrant vascular proliferation by blocking the mTOR/PI3K/AKT pathway and decreasing VEGF production $(9,26,31)$.

A recent paper published by Lin et al evaluated the effect of propranolol on infantile hemangiomas and demonstrated regression of the vascular lesions that was related to inhibition of the PI3K/AKT pathway (27).

Cases 1 and 2 diagnosed with CLM of the left hemithorax (case 1) and $\mathrm{CHH}$ (case 2) were both initially started on propranolol without a visible effect after 4 weeks of monotherapy.

Propranolol was initiated with starting doses of $0.5-1 \mathrm{mg} / \mathrm{kg} /$ day which was increased gradually up to a dose of $3 \mathrm{mg} / \mathrm{kg} /$ day for a better tolerance. Sirolimus was started on the lower recommended dose of $0.4-0.5 \mathrm{mg} / \mathrm{m}^{2}$ and was adjusted according to plasmatic levels. Our protocol for monitoring plasmatic levels of sirolimus was to draw the first test 7 days 
after the beginning of the treatment and then every other week for the duration of the patient admission in our unit. After a steady plasmatic level was reached, tests were drawn monthly.

Recommended plasmatic levels of sirolimus vary between reports ranging from 7.5-10, 10-15 and $12-20 \mathrm{ng} / \mathrm{ml}(9,10,19,22,30)$ while reported doses for newborns are $0.4-0.8 \mathrm{mg} / \mathrm{m}^{2}(9,10,17-19,32,33)$. Our aim was to use the lowest therapeutic dose of sirolimus to avoid potential side effects associated with the drug.

Despite suboptimal plasmatic levels, cases 1,2 and 3 showed impressive results starting in the first days of therapy. On the other hand, case 4 diagnosed with DCMO had higher than recommended plasmatic levels despite receiving lower doses of sirolimus (maximum plasmatic level of $26 \mathrm{ng} / \mathrm{ml}$ at a dose of $0.2 \mathrm{mg} / \mathrm{m}^{2}$ ). We could not explain this finding compared with the other patients in our report.

Studies on adult renal transplant patients on immunosuppressive therapy with sirolimus showed variations of plasmatic concentrations of sirolimus among patients receiving the same dose and an intrapatient variability in blood concentration. These variations are dependent on varying contents of enterocyte P-glycoprotein and CYP3A4 between individuals; both enterocyte P-glycoprotein and CYP3A4 being implicated in the metabolism of sirolimus (29).

Case 3 diagnosed with KHE of the left lower limb complicated with KMP required associative therapy with propranolol, sirolimus and methylprednisolone for 4 weeks until platelet levels reached a normal value.

Currently there is no consensus regarding first line of treatment for patients diagnosed with KHE with or without KMP. Medical therapy for patients with KHE and KMP includes corticosteroids, vincristine, propranolol, interferon and in recent years sirolimus (30). Regimens reported in the literature as first line therapies for patients with KHE are corticosteroid plus vincristine or corticosteroid plus sirolimus $(11,12,30,34)$.

Despite showing good initial response to combined antiproliferative therapy with sirolimus and propranolol, the patient developed lymphedema of the ipsilateral limb after 12 weeks of therapy. Giving the fast increase in thigh girth $(8 \mathrm{~cm}$ in 1 week) we decided to increase the dose of sirolimus to $2 \mathrm{mg} / \mathrm{m}^{2}$ and reintroduced methylprednisolone. We based our decision on a reported case by Chinello et al, where sirolimus was administered in doses up to $3 \mathrm{mg} / \mathrm{m}^{2}$ to maintain plasmatic levels between 7.5-10 $\mathrm{ng} / \mathrm{ml}$ (30).

Vincristine was introduced during the 13th week of combined antiproliferative therapy. After 8 rounds of vincristine, the patient showed diminished leg swelling (thigh girth decreased by $2 \mathrm{~cm}$ ), subcutaneous tissue became softer, less indurated and mobility of the limb improved.

A retrospective multicenter analysis conducted in 2018 by Ji et al concluded that lymphedema is a frequent sequalae found in patients diagnosed with KHE and that associated KMP or sirolimus treatment has no prediction in its development (35). KHE can predispose the patient secondary lymphedema through infiltration of the tumor in the lymphatic vessels or to primary lymphedema because of aberrant formation of the lymphatic vasculature with insufficient vessels $(35,36)$. Giving the reported evolution of patients with KHE with long term follow-up it is difficult to conclude whether vincristine or sirolimus may have any effect on lymphedema.
Response to treatment for case 4 was noted during the first days of therapy by changes in the color of the capillary lesions which became paler. Over time, no major changes were observed on the overall size of the limbs.

Prior to starting the treatment, all patients had blood tests drawn to check for baseline levels of complete blood count, acute inflammatory markers, liver and renal function tests, lipid profile and plasmatic electrolytes based on the most common adverse effects of sirolimus.

Adverse effects observed in our patients were concordant with reported cases in the literature $(9,10,14,17,19-22)$. Sirolimus is a new immunosuppressant drug originally approved for use in kidney transplant recipients, but no patient showed signs of infection/sepsis or hematologic changes throughout the course of treatment. Long-term administration at these dosages seems to be safe. All patients showed increased triglycerides. Cases 1 and 2 showed persistent hypertriglyceridemia that resolved after $\sim 10$ weeks of therapy while cases 3 and 4 showed inconsistent high triglyceride levels. Studies conducted on adult patients demonstrated that sirolimus increases liver synthesis of triglycerides by increasing lipase activity in the adipose tissue and/or decreasing lipoprotein lipase activity (37).

Before initiation of treatment, case 2 with $\mathrm{CHH}$ had elevated liver enzymes that remained over the normal reference range over the course of the first 20 weeks of therapy but we could not distinguish if this was an adverse effect of sirolimus or if the liver enzymes were elevated because of tissue destruction by the liver mass.

In conclusion, combined therapy with propranolol and sirolimus is a safe therapeutic choice for patients with congenital vascular anomalies with good outcomes and without life threatening adverse effects. More studies must be conducted to confirm our findings.

\section{Acknowledgements}

Not applicable.

\section{Funding}

No funding was received.

\section{Availability of data and materials}

More information concerning the 4 cases can be obtained from the corresponding author upon reasonable request.

\section{Authors' contributions}

CC conceived the presented idea and the study design, and provided final approval of the version to be published. AMB investigated the aspects of the case series. CM developed the theory and contributed to the computations of the data. SM and AIB collected the data of the patients for this study and verified the analytical methods. DS and VM helped supervise the project in view of the data collected. DAI and RIS investigated the aspects and supervised the findings of this work. All authors have read and approved the final manuscript for publication. 


\section{Ethics approval and consent to participate}

The study was approved by the Ethics Committee of 'Marie S. Curie' Emergency Clinical Hospital for Children. Patients who participated in this study had complete clinical data. Written informed consent to participate was signed by the patient's guardian/next of kin.

\section{Patient consent for publication}

Written informed consent was obtained from the minors' guardian/next of kin for publication of any identifiable images or data included in this article. The corresponding author is in possession of these documents.

\section{Competing interests}

The authors declare that they have no competing interests.

\section{References}

1. Rendón-Elíasa FG, Hernández-Sánchez M, Albores-Figueroa R, Montes-Tapia FF and Gómez-Danés LH: Congenital vascular malformations update. Med Univer 16: 184-198, 2014.

2. Behr GG and Johnson C: Vascular anomalies: Hemangiomas and beyond-part I, Fast-flow lesions. AJR Am J Roentgenol 200: 414-422, 2013

3. Behr GG and Johnson C: Vascular anomalies: Hemangiomas and beyond-part 2, Slow flow lesions. AJR Am J Roentgenol 200: 423-436, 2013

4. White CL, Olivieri B, Restrepo R, McKeon B, Karakas SP and Lee EY: Low-flow vascular malformation pitfalls: From clinical examination to practical imaging evaluation-part 1, lymphatic malformation mimickers. AJR Am J Roentgenol 206: 940-951, 2016.

5. Cox JA, Bartlett E and Lee EI: Vascular malformations: A review. Semin Plast Surg 28: 58-63, 2014.

6. Behravesh S, Yakes W, Gupta N, Naidu S, Chong BW, Khademhosseini A and Oklu R: Venous malformations: Clinical diagnosis and treatment. Cardiovasc Diagn Ther 6: 557-569, 2016

7. Zheng W, Aspelund A and Alitalo K: Lymphangiogenic factors, mechanisms and applications. J Clin Invest 124: 878-887, 2014.

8. Colbert SD, Seager L, HaiderF,Evans BT, Anand R andBrennan PA: Lymphatic malformations of the head and neck-current concepts in management. Br J Oral Maxilofac Surg 51: 98-102, 2013.

9. Amodeo I, Colnaghi M, Raffaeli G, Cavallaro G, Ciralli F, Gangi S, Leva E, Pignataro L, Borzani I, Pugni L and Mosca F: The use of sirolimus in the treatment of giant cystic lymphangioma: Four case reports and update of medical therapy. Medicine (Baltimore) 96: e8871, 2017.

10. Hammill AM, Wentzel MS, Gupta A, Nelson S, Lucky A, Elluru R, Dasgupta R, Azizkhan RG and Adams DM: Sirolimus for the treatment of complicated vascular anomalies in children. Clin Med Insights Blood Disord 57: 1018-1024, 2011.

11. Mahajan P, Margolin J and Iacobas I: Kasabach-merritt phenomenon: Classic presentation and management options. Clin Med Insights Blood Disord 10: 1179545X17699849, 2017.

12. Ji Y, Chen S, Yang K, Xia C and Li L: Kaposiform hemangioendothelioma: Current knowledge and future perspectives. Orphaneet J Rare Dis 15: 39, 2020.

13. Zhang B and Ma L: Updated classification and therapy of vascular malformations in pediatric patients. Pediatr Invest 2: 119-123, 2018.

14. Raphael MF, Breur JM, Vlasveld FA, Elbert NJ, Liem YT, Kon M, Breugem CC and Pasmans SG: Treatment of infantile hemangiomas: Therapeutic options in regard to side effects and adverse events-a review of the literature. Expert Opin Drug Saf 15: 199-214, 2016.

15. Droitcourt C, Kerbrat S, Rault C, Botrel MA,Happe A, Garlantezec R, Guillot B, Schleich JM, Oger E and Dupuy A: Safety of oral propranolol for infantile hemangioma. Pediatrics 141: e20173783, 2018.

16. Léauté-Labrèze C, Hoeger P, Mazereeuw-Hautier J, Guibaud L, Baselga E, Posiunas G,Phillips RJ, Caceres H, Lopez Gutierrez JC, Ballona R, et al: A randomized, controlled trial of oral propranolol in infantile hemangioma. N Engl J Med 372: 735-746, 2015.
17. Triana P, Miguel M, Díaz M, Cabrera M and López Gutiérrez JC: Oral sirolimus: An option in the management of neonates with life-threatening upper airway lymphatic malformations. Lymphat Res Biol 17: 504-511, 2019.

18. Wang Z, Yao W, Sun H, Dong K, Ma Y, Chen L, Zheng S and Li K: Sirolimus therapy for kaposiform hemangioendothelioma with long-term follow-up. J Dermatol 46: 956-961, 2019.

19. Adams DM, Trenor CC III, Hammill AM, Vinks AA, Patel MN, Chaudry G, Wentzel MS, Mobberley-Schuman PS, Campbell LM, Brookbank C, et al: Efficacy and safety of sirolimus in the treatment of complicated vascular anomalies. Pediatrics 137: e20153257, 2016.

20. Freixo C, Ferreira V, Martins J, Almeida R, Caldeira D, Rosa M, Costa J and Ferreira J: Efficacy and safety of sirolimus in the treatment of vascular anomalies: A systematic review. J Vasc Surg 71: 318-327, 2020.

21. Sandbank S, Molho-Pessach V, Farkas A, Barzilai A and Greenberger S: Oral and topical sirolimus for vascular anomalies: A multicentre study and review. Acta Derm Venereol 99: 990-996, 2019.

22. Honnorat M, Viremouneix L, Ayari S, Guibaud L, Coste K, Claris $\mathrm{O}$ and Butin M: Early adjuvant medication with the mTOR inhibitor sirolimus in a preterm neonate with compressive cystic lymphatic malformation. Front Pediatr 8: 418, 2020.

23. Cirstoveanu C, Bizubac M, Mustea C, Barascu I, Manolache S, Nine L, Istrate-Barzan A, Spataru R and Marcu V: Combined antiproliferative therapy with rapamycin and propranolol for giant congenital lymphangioma. Chest 157: A317, 2020.

24. Karar J and Maity A: PI3K/AKT/mTOR pathway in angiogenesis. Front Mol Neurosci 4: 51, 2011

25. Laplante M and Sabatini DM: mTOR signaling at a glance. J Cell Sci 122: 3589-3594, 2009

26. Greenberger S, Yuan S, Walsh LA, Boscolo E, Kang KT, Matthews B, Mulliken JB and Bischoff J: Rapamycin suppresses self-renewal and vasculogenic potential of stem cells isolated from infantile hemangioma. J Invest Dermatol 131: 2467-2476, 2011.

27. Lin Z, Wang L, Huang G, Wang W and Lin H: Propranolol inhibits the activity of PI3K, AKT, and HIF-1 $\alpha$ in infantile hemangiomas. Pediatr Surg Int 34: 1233-1238, 2018.

28. Pan WK, Li P, Guo ZT, Huang Q and Gao Y: Propranolol induces regression of hemangioma cells via the down-regulation of the PI3K/Akt/eNOS/VEGF pathway. Pediatr Blood Cancer 62: $1414-1420,2015$.

29. Mahalati $K$ and Kahan BD: Clinical pharmacokinetics of sirolimus. Clin Pharmacokinet 40: 573-585, 2001.

30. Chinello M, Di Carlo D, Olivieri F, Balter R, De Bortoli M, Vitale V, Zaccaron A, Bonetti E, Parisi A and Cesaro S: Successful management of kaposiform hemangioendothelioma with long-term sirolimus treatment: A case report and review of the literature. Mediterr J Hematol Infect Dis 10: e2018043, 2018.

31. Mukhopadhyay S, Frias MA, Chatterjee A, Yellen P and Foster DA: The enigma of rapamycin dosage. Mol Cancer Ther 15: 347-353, 2016.

32. Alaqeel AM, Alfurayh NA, Alhedyani AA and Alajlan SM: Sirolimus for treatment of kaposiform hemangioendothelioma associated with Kasabach-Merritt phenomenon. JAAD Case Rep 2: 457-461, 2016.

33. Warren D, Diaz L and Levy M: Diffuse hepatic hemangiomas successfully treated using sirolimus and high-dose propranolol. Pediatr Dermatol 34: e286-e287, 2017.

34. Drolet BA, Trenor CC III, Brandão LR, Chiu YE, Chun RH, Dasgupta R, Garzon MC, Hammill AM, Johnson CM, Tlougan B, et al: Consensus-derived practice standards plan for complicated Kaposiform hemangioendothelioma. J Pediatr 163: 285-291, 2013.

35. Ji Y, Chen S, Xia C, Zhou J, Jiang X, Xu X, Yang K, Zhang X, Kong F, Lu G and Zhang Y: Chronic lymphedema in patients with kaposiform hemangioendothelioma: Incidence, clinical features, risk factors and management. Orphanet J Rare Dis 15: 313, 2020.

36. Konczyk DJ, Goss JA, Maclellan RA and Greene AK: Association between extremity kaposiform hemangioendothelioma and lymphedema. Pediatr Dermatol 35: e92-e93, 2018.

37. Morrisett JD, Abdel-Fattah G and Kahan BD: Sirolimus changes lipid concentrations and lipoprotein metabolism in kidney transplant recipients. Transplant Proc 35(3 Suppl): 143S-150S, 2003. International (CC BY-NC-ND 4.0) License. 